\title{
Response to commentary "Zinc is decreased in prostate cancer: an established relationship of prostate cancer!"
}

\author{
Agnieszka Maria Banas $\cdot$ Krzysztof Banas
}

Received: 16 November 2010/ Accepted: 16 November 2010/Published online: 8 December 2010

(C) The Author(s) 2010. This article is published with open access at Springerlink.com

\begin{abstract}
"Zinc is decreased in prostate cancer: an established relationship of prostate cancer!"- this is the title of the critique of our paper [1], published in this volume. According to the authors (Costello and Franklin), we presented our results concerning zinc concentration "in the context of refutation of the established relationship" showing "widespread recalcitrance and/or lack of knowledge within the clinical and biomedical research community for recognition that zinc decrease[s] in prostate cancer."

In fact, our initial motivation for the analysis of manganese, iron, copper, and zinc concentrations in prostate cancer tissues was based on the lack of established relationships of these elements with prostate cancer development. In our paper we showed only results of our work and stated: "It is clear that further studies with a larger number of tissue samples must be performed to consolidate the present conclusions." We did not claim that our results should be treated like dogma, so it is really incomprehensible why we deserved such an aggressive critique.

In our paper we demonstrated results (based on the analysis of 12 patients-we did not claim that the number of cases we presented is enough to draw any clinically important conclusions) that zinc concentrations are increased in prostate cancer, but the data presented by us are only part of our work concerning the influence of selected trace elements on prostate cancer development. We did not focus only on the role of zinc in cancerogenesis; that is why our literature discussion regarding zinc
\end{abstract}

A. M. Banas $(\bowtie) \cdot K$. Banas

Singapore Synchrotron Light Source,

National University of Singapore,

5 Research Link, Singapore 117603, Singapore

e-mail: slsba@nus.edu.sg levels in prostate cancer tissues was limited only to a few papers published within the last decade.

In our opinion, if one needs to build theory and draw conclusions about the biochemical processes that take place at the cellular level, one must have information about elemental concentrations with similar special resolution. As far as we know, in most experiments macroscopic samples or samples homogenized or mineralized prior to the experiments have been used for data collection. Table 1 presents various sample preparation techniques and methods used by the authors of papers mentioned by Costello and Franklin in their Table 2.

As can be seen from the data presented, analysis of these types of samples can provide only average values for zinc concentrations, which by no means are representative. But what is more important is that various sample treatments may influence the final results. Nobody can follow very precisely processes occurring after adding different chemicals to the sample homogenates.

Our experiments for quantitative analysis used a beam collimated to $15 \mu \mathrm{m}$, with the live view of the position of the beam with respect to the sample observed using the microscope. The evaluation of the grading (Gleason score) of the chosen areas was double-checked by a histopathologist. We tried our best to analyze only the area selected earlier by the experienced histopathologist to obtain reliable information about zinc concentrations. Costello and Franklin seriously questioned the reliability of our study, saying that "there is no identification of the tissue/cell composition that the beam is detecting. This raises questions such as the measurement including stroma, including luminal prostatic fluid, being secretory or basal cell, and other possibilities." In our opinion, our experiment is one of the methods that can give full control over which type of cells is being analyzed. Unfortunately, the authors mentioned by Costello and 


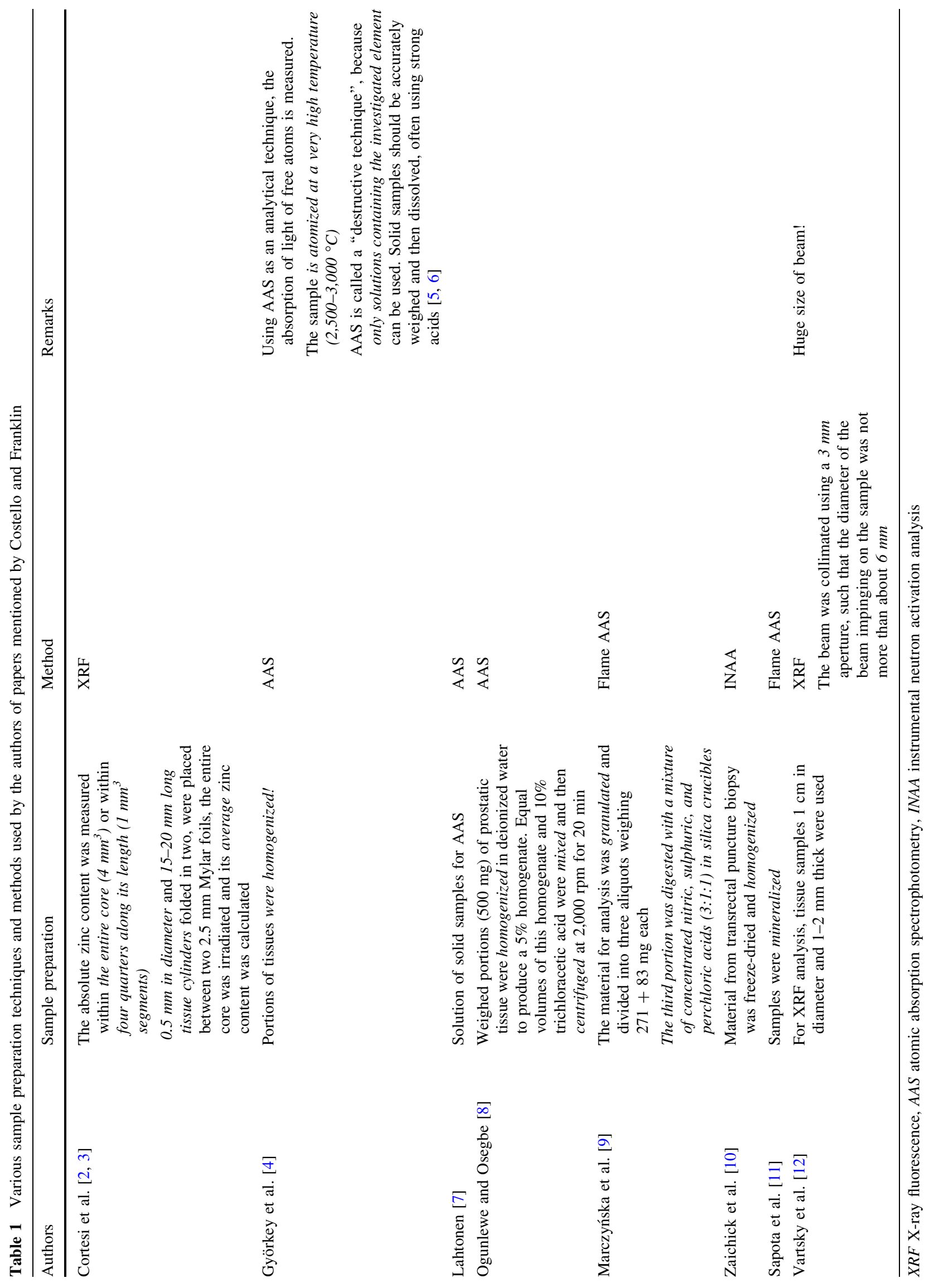


Fig. 1 Histological view of human tissue with the map of the distribution of zinc concentration. Three different transparency values are chosen to show the correspondence between the tissue constituents and the distribution of the element
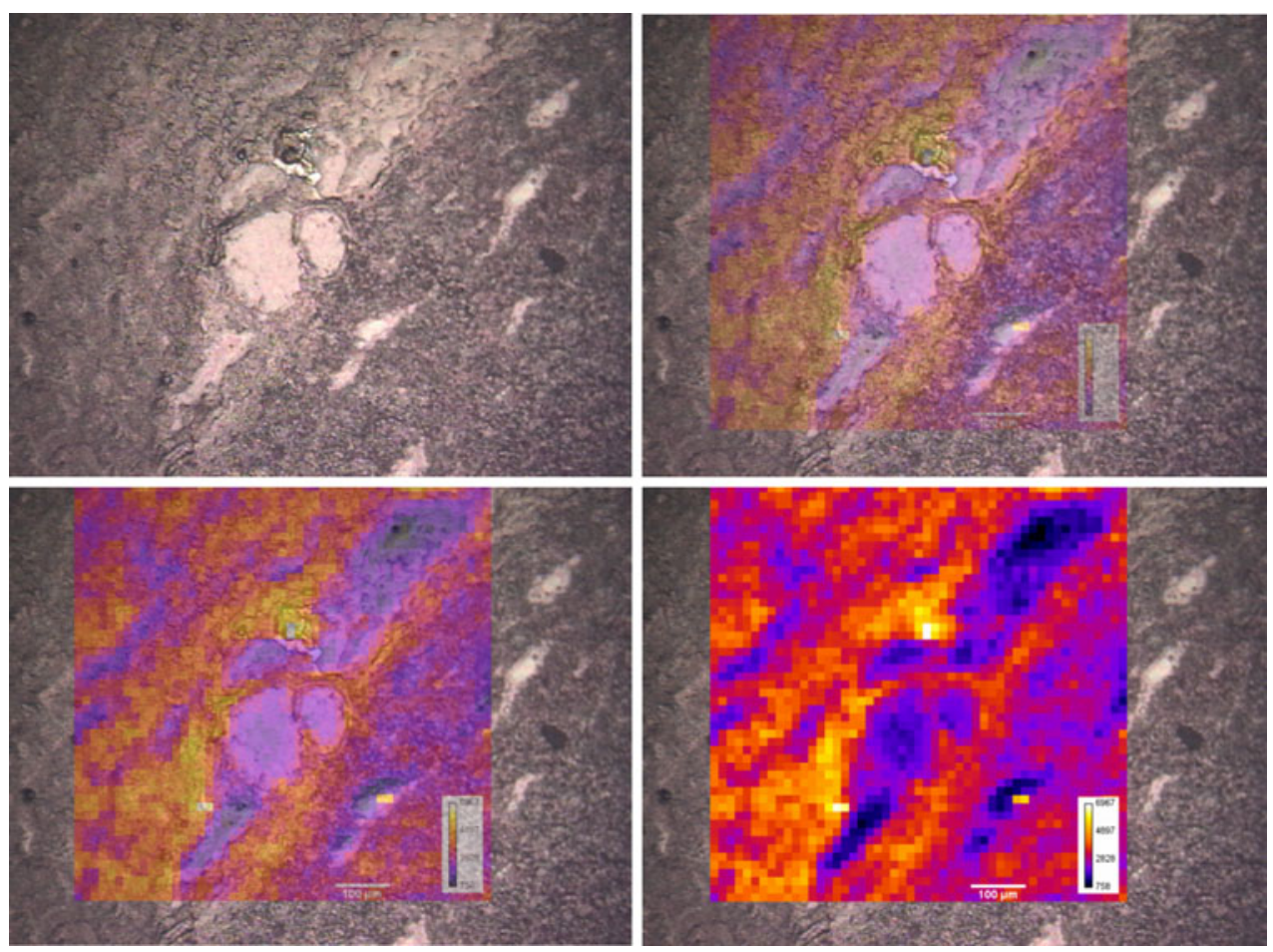

Fig. 2 Calculated mean values of zinc in three different locations marked on the 2D map

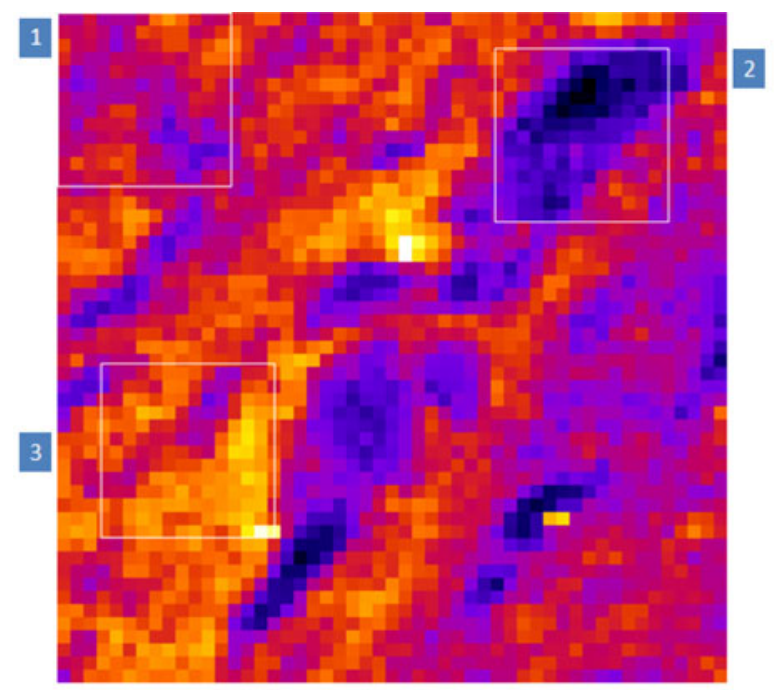

\begin{tabular}{|c|c|c|c|c|c|c|}
\hline Label & $\begin{array}{c}\text { Area } \\
{\left[\mu m^{2}\right]}\end{array}$ & $\begin{array}{l}\text { Mean } \\
\text { [a.u] }\end{array}$ & $\begin{array}{c}\text { StdDev } \\
\text { [a.u] }\end{array}$ & Min [a.u] & $\begin{array}{l}\text { Max } \\
\text { [a.u] }\end{array}$ & $\begin{array}{c}\text { Median } \\
\text { [a.u] }\end{array}$ \\
\hline 1 matrix_Zn_ROI_1 & 39800.2 & 3018.4 & 522.3 & 1841 & 4680 & 3011 \\
\hline 2 matrix_Zn_ROI_2 & 39800.2 & 2138.2 & 752.9 & 758 & 4107 & 1928.8 \\
\hline 3 matrix_Zn_ROI_3 & 39800.2 & 3991.2 & 843.4 & 2023 & 6633 & 3976.8 \\
\hline
\end{tabular}

Franklin in their Table 2 could not do this verification during their experiments; even Costello and Franklin themselves claimed that these authors analyzed differing mixtures of tissue components. It is very unclear to us why our method should be considered dubious by Costello and Franklin while at the same time the other analyses of macro, homogenized, mineralized, granulated samples (frankly speaking, destroyed samples) should be favored by them.

Another issue is the problem of finding representative samples for the healthy category.

Often tissues for this purpose are collected during postmortem examination. In this case it is hard to say that 
the patient was healthy. Even if histopathology of the prostatic gland does not reveal any cancerous changes, zinc and other elemental concentrations could be altered owing to antemortem stress and postmortem changes.

We are far away from discrediting any previous results obtained in this research area, but we do believe that no one should be offended or accused of incompetence only because the results are different from those obtained previously. We did our best with the sample preparation, experiments, and data evaluation processes.

As proof that only analysis performed at the cellular level can provide reliable and true information about the concentration of any element in a selected area, we would like to present the following example. Figure 1 shows a histological view of human tissue with a map of the distribution of zinc concentration. Three different transparency values are chosen to show the correspondence between the tissue constituents and the distribution of the element. The main goal of this presentation is to illustrate that, despite the fact that this sample was described as cancerous by the histopathologist, it is highly nonuniform and, depending on the point we choose, different values of zinc concentration may be obtained. The size of the map is approximately $750 \mu \mathrm{m}$ by $750 \mu \mathrm{m}$. To exemplify the possible pitfalls, we present the calculation of the mean value of the integrated area under the $\mathrm{K}_{\alpha}$ peak for zinc ( $E=8.639 \mathrm{keV})$, which is proportional to the concentration of zinc atoms in the tissue. We assume in this calculation that the sampled area is $39,800 \mu \mathrm{m}^{2}$ (which corresponds to a beam size of around $200 \mu \mathrm{m}$ ). As one can clearly see in Fig. 2, the calculated values strongly depend on the location of the region of interest. This variation could be even more profound in cases where the sampled area is bigger (like in many previous experiments in which the samples under investigation were whole collected biopsy prostate tissue).

We did not carry out quantitative analysis based on these experiments because the time for a single experiment must be short (around 3 or $5 \mathrm{~s}$ ). This kind of analysis was only used for qualitative evaluation of the distribution of the elements within the tissue.

We hope that other researchers will soon conduct similar experiments using a microbeam.

Another important point is the division of the results into categories. Many researchers reported only results for two or three groups (healthy, cancerous, and sometimes hyperplastic). In our case, by using synchrotron radiation and the microbeam focused to $15 \mu \mathrm{m}$, we were able to select areas with different Gleason scores and present the results separately for these categories. As one can see in Fig. 3, the highest concentration of zinc is observed for samples with Gleason grade 2 (early stage of cancer development). If we present exactly the same data divided
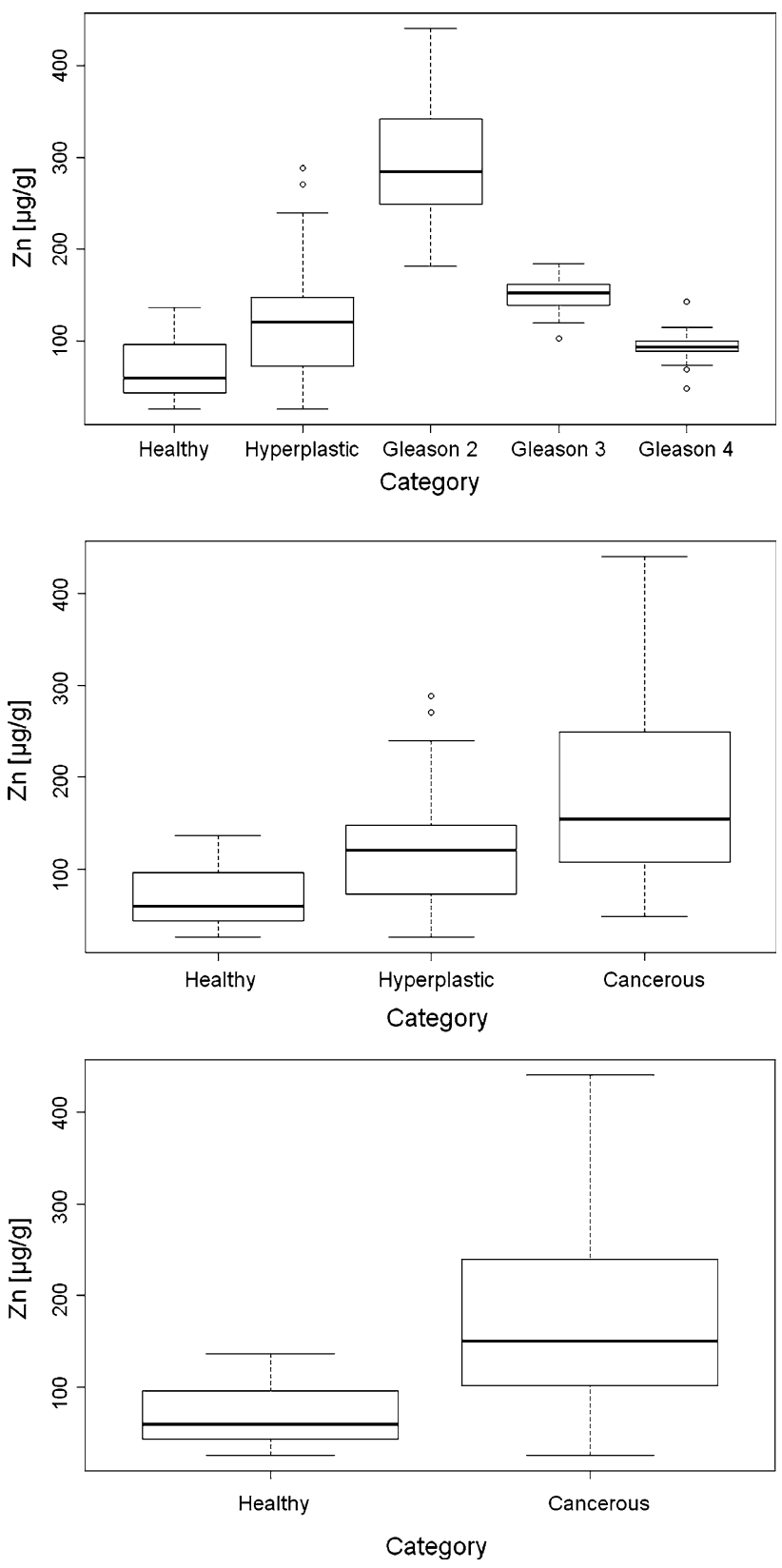

Fig. 3 Box plots presenting the distribution of the zinc concentration for different category assignments

only into three or two categories, the calculated mean values for cancerous tissues are lower.

We strongly believe that any well-established relationship should not appear in science just by repeating it dozens of times. As the authors of the commentary wrote, "the public is dependent upon accurate and reliable information disseminated by the medical and scientific community, and inaccurate information does harm to the public interest." We could not agree more if it also allows the presentation of data that are contradictory to "the well-established relationship." Progress in science is only possible if we accept the possibility that former findings might not be accurate. 
Again we could speak with the authors of the commentary in one voice that "an accurate understanding of the zinc relationship and its tumor suppressor activities is essential." In our opinion, to accomplish this task we do need reliable information about the concentration distribution of the essential elements with decent special resolution. We hope that our findings stimulate future progress toward understanding the complex relationship between zinc levels and prostate carcinogenesis.

Open Access This article is distributed under the terms of the Creative Commons Attribution Noncommercial License which permits any noncommercial use, distribution, and reproduction in any medium, provided the original author(s) and source are credited.

\section{References}

1. Banas A, Kwiatek WM, Banas K, Gajda M, Pawlicki B, Cichocki $\mathrm{T}$ (2010) J Biol Inorg Chem 15(7):1147-1155
2. Cortesi M, Fridman E, Volkov A, Shilstein SSh, Chechik R, Breskin A, Vartsky D, Raviv G, Ramon J (2010) Prostate 70:1701-1708

3. Cortesi M, Fridman E, Volkov A, Shilstein SSh, Chechik R, Breskin A, Vartsky D, Kleinman N, Kogan G, Moriel E, Gladysh V, Huszar M, Ramon J, Raviv G (2008) Prostate 68:994-1006

4. Györkey F, Min KW, Huff JA, Györkey P (1967) Cancer Res 27:1348-1353

5. Skoog DA, West DM, Holler FJ (1992) Fundamentals of analytical chemistry. Saunders College Publishing, Fort Worth

6. Kenkel J (1994) Analytical chemistry for technicians. Lewis Publishers, Boca Raton

7. Lahtonen R (1985) Prostate 6:177-183

8. Ogunlewe JO, Osegbe DN (1989) Cancer 63:1388-1392

9. Marczyńska A, Kulpa J, Leńko J (1983) Int Urol Nephrol 15:257-265

10. Zaichick VY, Sviridova TV, Zaichick S (1997) Int Urol Nephrol 29:565-574

11. Sapota A, Daragó A, Taczalski J, Kilanowicz A (2010) Biometals 22:1041-1049

12. Vartsky D, Shilstein S, Bercovich A, Huszar M, Breskin A, Chechik R, Korotinsky S, Malnick SD, Moriel E (2003) J Urol 70:2258-2262 